\section{(6) OPEN ACCESS}

\title{
Non-classical monocytes as mediators of tissue destruction in arthritis
}

\author{
Antonia Puchner, ${ }^{1}$ Victoria Saferding, ${ }_{1}^{1}$ Michael Bonelli, ${ }^{1}$ Yohei Mikami, ${ }^{2}$ \\ Melanie Hofmann, ${ }^{1}$ Julia S Brunner, ${ }^{1}$ Michael Caldera, ${ }^{3}$ Eliana Goncalves-Alves, ${ }^{1}$ \\ Nikolaus B Binder, ${ }_{1}^{1}$ Anita Fischer, ${ }^{1}$ Elisabeth Simader, ${ }^{1}$ Carl-Walter Steiner, ${ }^{1}$ \\ Harald Leiss, ${ }^{1}$ Silvia Hayer, ${ }^{1}$ Birgit Niederreiter, ${ }^{1}$ Thomas Karonitsch, ${ }^{1}$ \\ Marije I Koenders, ${ }^{4}$ Bruno K Podesser, ${ }^{5}$ John J O'Shea, ${ }^{2}$ Jörg Menche, ${ }^{3}$ Josef S Smolen, ${ }^{1}$ \\ Kurt Redlich, ${ }^{1}$ Stephan Blüml ${ }^{1,6}$
}

\begin{abstract}
Handling editor David S Pisetsky

- Additional material is published online only. To view please visit the journal online (http://dx.doi.org/10.1136/ annrheumdis-2018-213250).
\end{abstract}

'Division of Rheumatology, Department of Internal Medicine III, Medical University of Vienna, Vienna, Austria

${ }^{2}$ Molecular Immunology and Inflammation Branch, NIAMS, National Institutes of Health, Bethesda, Maryland, USA ${ }^{3}$ CeMM Research Center for Molecular Medicine of the Austrian Academy of Sciences, Vienna, Austria

${ }^{4}$ Department of Experimental Rheumatology, Radboud University Medical Center, Nijmegen, The Netherlands ${ }^{5}$ Department of Biomedical Research, Medical University of Vienna, Vienna, Austria ${ }^{6}$ Christian Doppler Laboratory for Arginine Metabolism in Rheumatoid Arthritis and Multiple Sclerosis, Vienna, Austria

\section{Correspondence to} Dr Antonia Puchner, Division of Rheumatology, Internal Medicine III, Medical University of Vienna, Vienna 1090, Austria; antonia.puchner@meduniwien. ac.at

Received 14 February 2018 Revised 30 April 2018 Accepted 9 June 2018 Published Online First 29 June 2018

\section{Check for updates}

To cite: Puchner $A$, Saferding V, Bonelli M, et al. Ann Rheum Dis 2018:77:1490-1497.

\section{ABSTRACT}

Objectives Bone destruction in rheumatoid arthritis is mediated by osteoclasts (OC), which are derived from precursor cells of the myeloid lineage. The role of the two monocyte subsets, classical monocytes (expressing CD115, Ly6C and CCR2) and non-classical monocytes (which are CD115 positive, but low in Ly6C and CCR2), in serving as precursors for $\mathrm{OC}$ in arthritis is still elusive. Methods We investigated CCR2 ${ }^{-1-}$ mice, which lack circulating classical monocytes, crossed into hTNFtg mice for the extent of joint damage. We analysed monocyte subsets in hTNFtg and K/BxN serum transfer arthritis by flow cytometry. We sorted monocyte subsets and analysed their potential to differentiate into $O C$ and their transcriptional response in response to RANKL by RNA sequencing. With these data, we performed a gene ontology enrichment analysis and gene set enrichment analysis.

Results We show that in hTNFtg arthritis local bone erosion and $\mathrm{OC}$ generation are even enhanced in the absence of CCR2. We further show the numbers of non-classical monocytes in blood are elevated and are significantly correlated with histological signs of joint destruction. Sorted non-classical monocytes display an increased capacity to differentiate into OCs. This is associated with an increased expression of signal transduction components of RANK, most importantly TRAF6, leading to an increased responsiveness to RANKL.

Conclusion Therefore, non-classical monocytes are pivotal cells in arthritis tissue damage and a possible target for therapeutically intervention for the prevention of inflammatory joint damage.

\section{INTRODUCTION}

In patients with inflammatory arthritis, joint destruction is the most serious consequence of the disease, as it leads to irreversible functional impairment. ${ }^{12}$ Destruction of the articular bone has been demonstrated to be almost exclusively mediated by osteoclasts (OC), multinucleated cells of myeloid origin generated from monocytic/ macrophage like precursors, which are still poorly defined. $^{3-7}$

The importance of $\mathrm{OC}$ in erosive arthritis has been shown in various experimental murine models; in the absence of receptor activator NF- $\kappa \mathrm{B}$ ligand (RANKL) or c-fos, arthritic mice are fully protected against bone damage despite the presence of severe synovial inflammation. ${ }^{46}$ The life span of individual OC has been estimated to be only a few weeks; therefore, they have to be replaced by a perpetual supply of osteoclast precursors (pOCs). ${ }^{8}$ Peripheral blood monocytes are potential precursors for OC, as both in humans and in mice monocytes can be driven to differentiate into OCs on stimulation with M-CSF and RANKL and increased frequencies of potential pOCs have been identified in patients with inflammatory arthritides. ${ }^{3} 8-11$ Based on the expression of lymphocyte antigen 6 complex (Ly6C) and chemokine receptor 2 (CCR2) monocytes can be further subdivided into inflammatory or classical monocytes expressing CD11b, CD115, Ly6C and CCR2 and resident or non-classical monocytes, which do not express Ly6C and CCR2 $2^{12-14}$. The chemokine receptor CCR2 has been shown to be important in the biology of inflammatory monocytes, as mice lacking this receptor show greatly reduced numbers of circulating inflammatory monocytes. ${ }^{15} 16$ CCR2-deficient mice have been used in several experimental models of autoinflammatory/autoimmune diseases to show that classical monocytes are the culprits of pathology that mediate tissue damage, since CCR2-deficient mice were protected against these diseases. ${ }^{17-19}$ However, in arthritis, the role of monocyte subsets is controversial. It is known that haematopoietic cells including monocytes are recruited to the site of inflammation and differentiate into macrophages and OCs locally in the synovial membrane. ${ }^{20}$ However, it is still unclear if there are committed pOCs or if all monocytes/ macrophages have the potential to become OCs. In this regard, the role of the two monocyte subsets in mediating joint destruction and in particular their role as pOCs during arthritis is conflicting, as some reports showed an important role of CCR $2^{+}$cells and thus classical monocytes as $\mathrm{OC}$ precursors in arthritis as well as osteoporosis, whereas others claimed non-classical monocytes to be critically important for joint inflammation. ${ }^{21-23}$ Of particular note, CCR2-deficient mice develop more severe (and more destructive) arthritis in several experimental models. $^{21} 22$ 24-26 
A
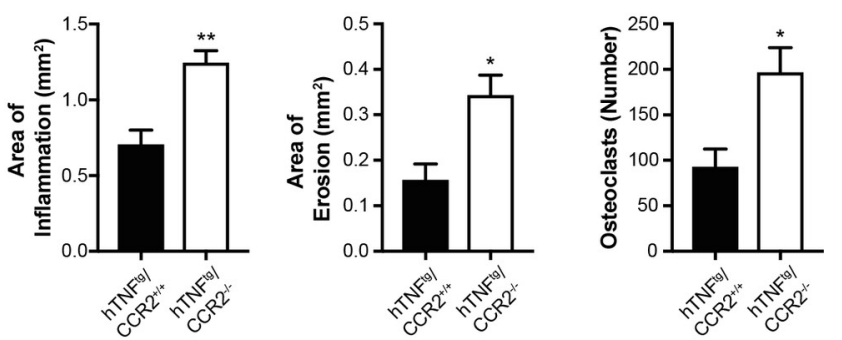

B

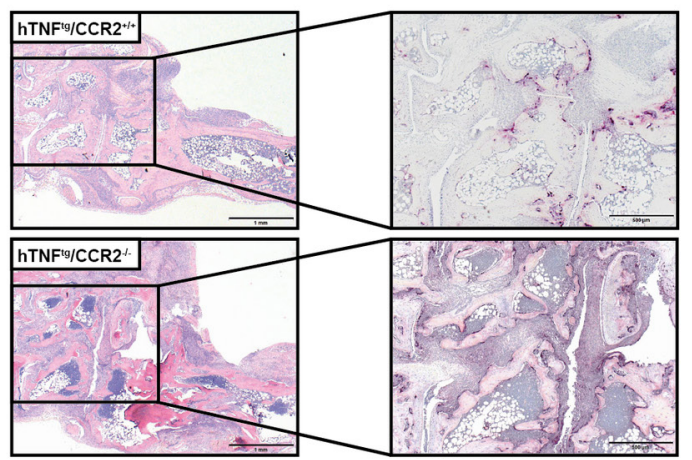

C
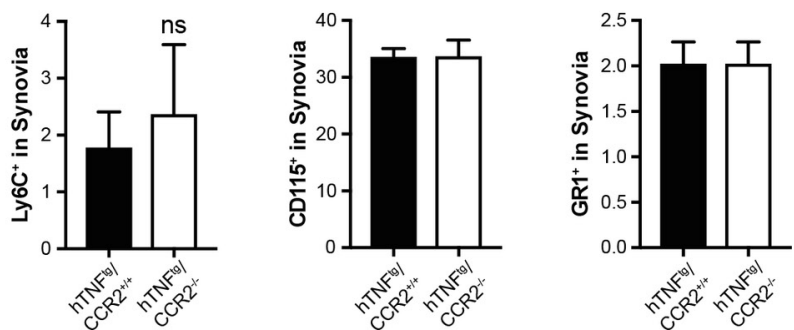

Figure $1 \mathrm{hTNFtg/CCR2}{ }^{-/-}$-deficient mice showed enhanced local bone destruction and osteoclast formation. CCR2 ${ }^{-1-}$ mice were crossed into hTNFtg mice and histological analysis was performed. (A) Quantitative analysis of histological parameters of arthritis (hTNFtg, n=5; hTNFtg/ $\left.\mathrm{CCR}^{-{ }^{--}}, \mathrm{n}=9\right)$ ). Results are shown as mean $\pm \mathrm{SEM}(\mathrm{B})$ Representative histological sections of the hind paws of hTNFtg/CCR2 ${ }^{+/+}$and hTNFtg/ $\mathrm{CCR}^{-/-}$mice stained with H\&E and TRAP. Osteoclasts are displayed as purple-stained cells. ${ }^{*} \mathrm{P}<0.05$. (C), Analysis of the percentage of Ly6C $\mathrm{C}^{+}$ cells (left panel), CD115 ${ }^{+}$cells (middle panel) and Gr1 ${ }^{+}$cells (right panel) shown as per cent of total cells in the synovial membrane of hTNFtg/CCR2 ${ }^{+/+}$and hTNFtg/CCR2 $^{-/-}$mice. TRAP, tartrate-resistant acid phosphatase.

\section{MATERIALS AND METHODS}

\section{Animals and arthritis models}

The heterozygous human TNF transgenic (hTNFtg) Tg197 mouse strain has been described previously. ${ }^{27} \mathrm{CCR} 2 \%$ mice on the $\mathrm{C} 57 \mathrm{bl} / 6$ genetic background were purchased from Jackson Laboratories and crossed into hTNFtg animals. Arthritis was evaluated weekly in a blinded manner as described previously. ${ }^{6}$

Serum-transfer arthritis was induced by intraperitoneal application of $150 \mu \mathrm{l}$ of $\mathrm{K} / \mathrm{BxN}$ serum on day 0 and day 2 as described. $^{28}$

All animal studies were approved by the animal ethics committee of the Medical University Vienna and comply with institutional guidelines.

\section{Histology and immunohistochemistry}

Histological sections of hind paws from wild type (WT) hTNFtg and hTNFtg/CCR2 ${ }^{-/}$mice, serum transfer arthritis as well as the Tissue Quest analysis were prepared and analysed as previously described. ${ }^{6} 2029$

\section{Flow cytometry and cell sorting}

Blood was collected every other week starting at 4 weeks of age until the end of the experiment (week 10 for hTNFtg, day 12 for $\mathrm{K} / \mathrm{BxN}$ serum transfer arthritis). Cells were simultaneously stained for CD11b (PerCP-Cy5.5-conj., clone M1/70), CD115 (PE-conj., clone AFS98) Ly6-G (FITC-conj., clone RB6-8C5, all eBioscience) and Ly6-C (PE-Cy7-conj., clone AL-21) and CD11c (APC-Cy7-conj., clone HL3, all BD Pharmingen). Classical monocytes were characterised as $\mathrm{CD} 11 \mathrm{~b}^{+} \mathrm{CD} 115^{+} \mathrm{Ly} 6 \mathrm{C}^{+}$ and non-classical monocytes as $\mathrm{CD}_{11} \mathrm{~b}^{+} \mathrm{CD} 115^{+} \mathrm{Ly} 6 \mathrm{C}^{-}$cells. For flow-cytometric analyses, we used a BD FACSCanto II (Becton Dickinson Immunocytometry Systems, San Jose, California, USA).

For cell sorting, pooled peripheral blood cells from either hTNFtg or WT mice were stained with CD11b, CD115 and Ly6-C antibodies and then isolated using a BD FACSAria II sorter.

\section{In vitro OC generation}

For in vitro OC formation, we sorted classical and non-classical monocytes from WT or arthritic hTNFtg mice. Cells were cultured in MEM-alpha supplemented with 10\% fetal bovine serum (FBS) in the presence of $100 \mathrm{ng} / \mathrm{mL}$ M-CSF for 3 days, then MEM-alpha with $10 \%$ FBS and $30 \mathrm{ng} / \mathrm{mL} \mathrm{M-CSF}$ and $50 \mathrm{ng} / \mathrm{mL}$ RANKL. After 4 days, we performed tartrate-resistant acid phosphatase (TRAP) staining and determined the amount of OCs (TRAP positive and three or more nuclei) and also counted the numbers of nuclei.

\section{RNA-sequencing}

Total RNA was prepared from approximately 1 million WT classical and non-classical monocytes by using mirVana miRNA Isolation Kit (AM1560, ABI). Two hundred nanograms of total RNA was subsequently used to prepare RNA-seq library by using TruSeq SR RNA sample prep kit (FC-122-1001, Illumina), following the manufacturer's protocol. The libraries were sequenced for 50 cycles (single read) with a HiSeq 2000 (Illumina). Raw sequencing data were processed with CASAVA 1.8.2 to generate FastQ files. Sequence reads were mapped onto the mouse genome build $\mathrm{mm} 9$ using TopHat 2.0. Gene expression values (RPKM, reads per kilobase exon per million mapped reads) were calculated with Cufflinks 2.0. All downstream statistical analyses, including PCA, were performed with Partek Genomics Suite 6.6, R 3.0.1 and GeneSpring GX 12.1 (Agilent Technologies).

\section{Western blotting}

Sorted classical and non-classical monocytes were cultured in the presence of $100 \mathrm{ng} / \mathrm{mL}$ M-CSF for 3 days or an additional 24 hours with RANKL (DC-STAMP) and then lysed in radioimmunoprecipitation (RIPA) buffer supplemented with phosphatase and protease inhibitors (Roche). Western blotting (WB) was performed as described. ${ }^{29}$ Primary antibodies used: Actin (Cytoskeleton), TRAF6 (Santa Cruz), DC-STAMP (Merck).

\section{GO term enrichment analysis}

Functional gene annotations were obtained from the Gene Ontology (GO) database. ${ }^{30} 31$ Gene set enrichment analyses were performed using Fisher's exact test with all approved protein coding genes from the HUGO Gene Nomenclature 
A

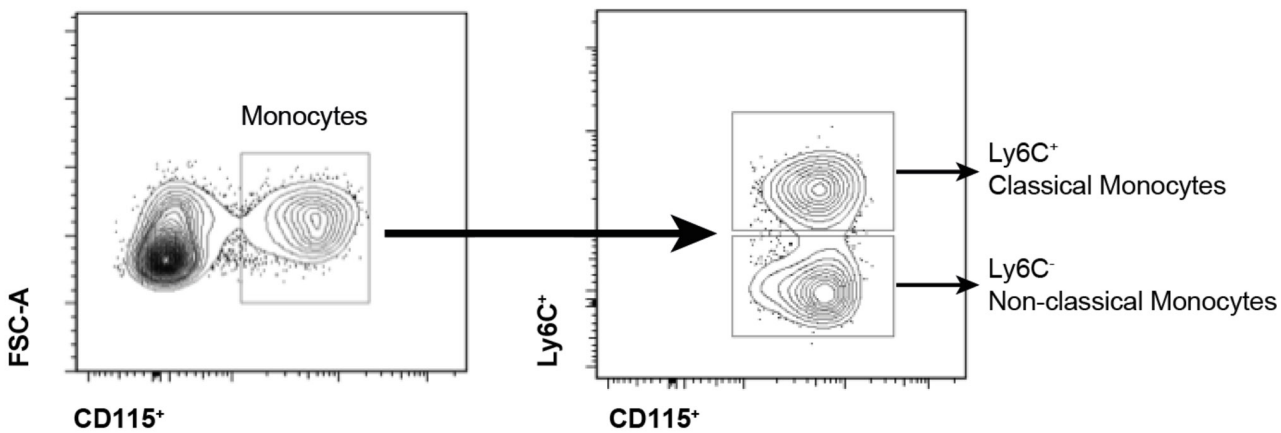

B
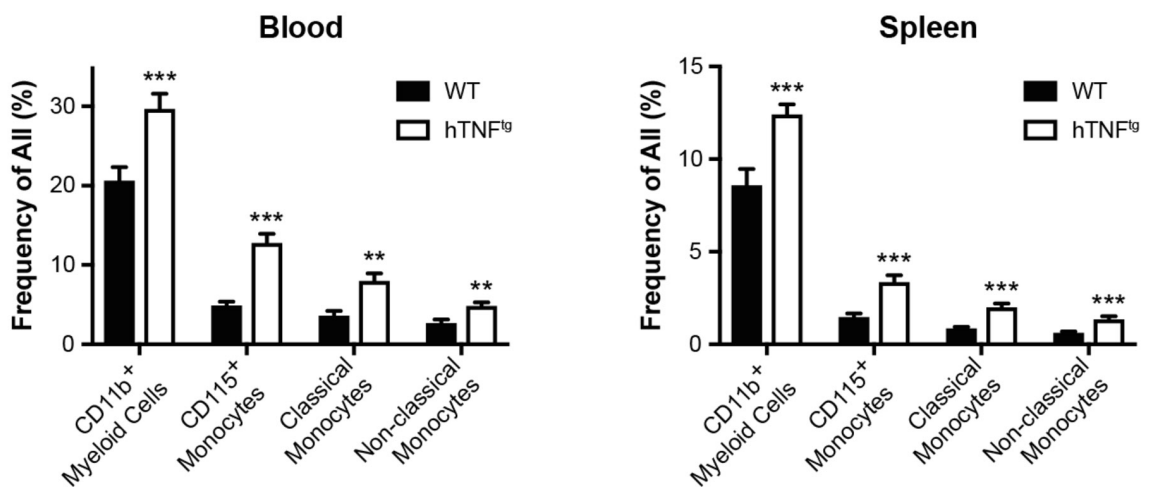

Figure 2 Monocytes in blood and spleen in hTNFtg arthritis. (A) Gating of flow cytometric analysis of myeloid populations in blood obtained from WT and hTNFtg mice. $(B, C)$ Bar graph summarising frequencies of myeloid populations in blood $(B)$ and spleen $(C)$ of WT mice and hTNFtg mice ( $n=$ at least 10 per group). Results are shown as mean \pm SEM. ${ }^{*}{ }^{*} \mathrm{P}<0.01 ;{ }^{*}{ }^{*} \mathrm{P}<0.001$. WT, wild type.

Committee (HGNC) as background set. ${ }^{32}$ The resulting $\mathrm{p}$ values were corrected for multiple hypotheses testing according to the Bonferroni procedure using a cut-off of $p<0.05$. In order to remove redundant GO terms, we summarised all terms with a semantic similarity of 0.7 or higher and represented them by their most informative common ancestor with the GO tree.

\section{Statistical analysis}

Data are presented as the means \pm SEM. We compared group mean values, as appropriate, by Student's unpaired two-tailed t-test or one-way analysis of variance with Bonferroni's multiple comparison test (Graph Pad Prism). We considered $\mathrm{p}<0.05$ significant.

\section{RESULTS}

\section{Increased joint damage in CCR2-deficient hTNFtg mice}

CCR2 deficiency has been shown to aggravate arthritis in interleukin1 receptor antagonist (IL1-RA) ${ }^{-/-}$mice as well as in collagen-induced arthritis (CIA). ${ }^{25}{ }^{26}$ In our first experiment we tested, whether reduction of circulating classical monocytes altered the extent of arthritis and joint damage also in hTNFtg mice. To this end, we crossed CCR2-deficient mice into hTNFtg mice, generating hTNFtg/CCR $2^{-/-}$mice. We detected increased synovial inflammation (figure 1), consistent with the results obtained in other models of arthritis. hTNFtg/ $\mathrm{CCR}^{-1-}$ mice also showed a significant increase in the extent of erosive bone damage and local generation of OC compared with hTNFtg mice (figure 1A, B). Analysing the composition of the inflammatory infiltrate, we detected only few $\mathrm{Ly}_{6 \mathrm{C}^{+}}$cells in the inflamed synovium (figure 1C). There were numerically increased numbers of $\mathrm{CD} 115^{+}$cells but fewer $\mathrm{Gr} 1^{+}$neutrophil granulocytes in hTNFtg/CCR2 $2^{-/-}$mice compared with hTNFtg mice (figure $1 \mathrm{C}$ ). Of note, we detected a significant retention of $\mathrm{Ly} 6 \mathrm{C}^{+}$cells in the bone marrow of hTNFtg/CCR $2^{-/-}$mice, in accordance with the published phenotype of CCR2-deficient mice (online supplementary figure S1). Therefore, although Ly $6 \mathrm{C}^{+}$cells are retained in the bone marrow also in the hTNFtg model in CCR2-deficient mice, tissue damage is not reduced, but even enhanced.

\section{Non-classical monocytes are elevated in hTNFtg arthritis}

We next analysed the relative numbers of myeloid cells in blood and spleens of WT and hTNFtg mice by flow cytometry. We detected significantly increased proportions of $\mathrm{CD}_{1} 1 \mathrm{~b}^{+}$myeloid cells and CD $115^{+}$monocytes in blood and spleens of hTNFtg compared with WT mice (figure $2 \mathrm{~B}, \mathrm{C}$ ). Both $\mathrm{CD} 11 \mathrm{~b}^{+} \mathrm{C}$ -

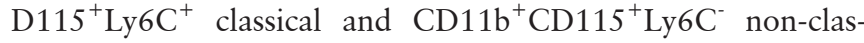
sical monocytes were significantly elevated in blood and spleen, suggesting altered composition of myeloid cells in hTNFtg mice (figure 2B, C). In hTNFtg mice, arthritis can be detected around week 5 of age (figure $3 \mathrm{~A}$ ). We therefore analysed blood of mice starting at 4 weeks of age, when no clinical symptoms of arthritis are detectable. We found that total numbers of CD $115^{+}$monocytes were significantly increased compared with WT animals already at 4 weeks of age and remained elevated at every time point measured (week, 4, 6, 8 and 10) (figure 3B). Analysing classical monocytes, we found a significant increase of these cells only from week 6 onwards. Non-classical monocytes, however, 

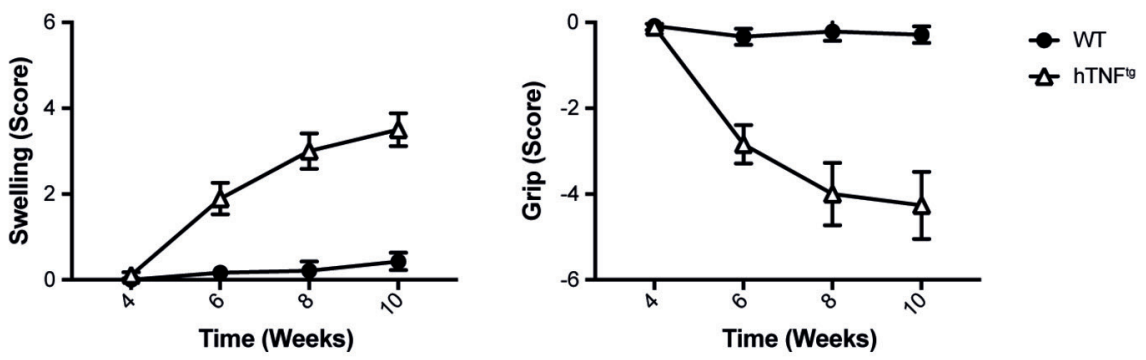

B
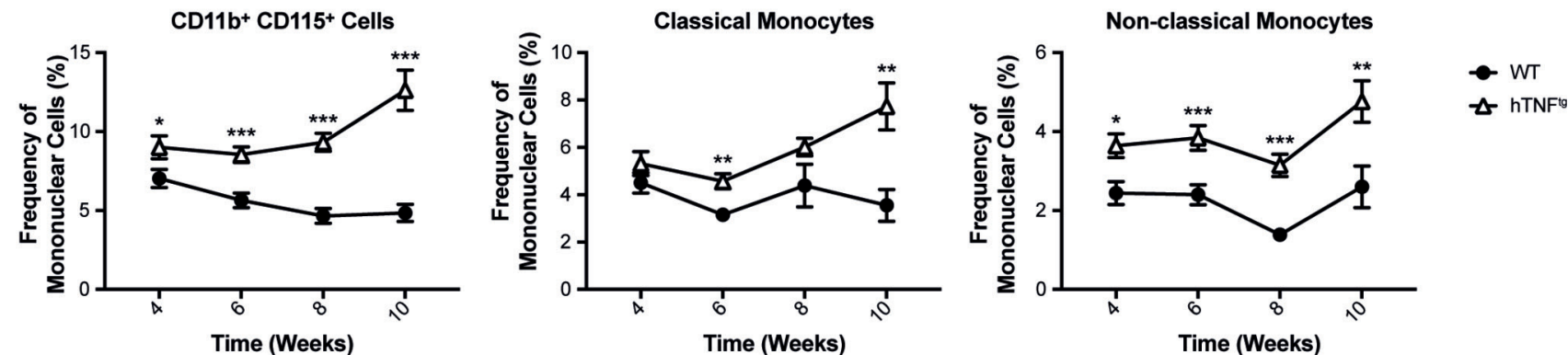

Figure 3 Development of arthritis is accompanied by accumulation of circulating mononuclear cells. (A) Clinical assessment of paw swelling and grip strength in WT mice $(n=10)$ and hTNFtg mice $(n=9)$. (B) Characterisation of monocytes under steady-state conditions and during hTNF driven arthritis. Blood from WT mice and hTNFtg were analysed using flow cytometric analysis over time ( $\mathrm{n}=$ at least 12 per group and time point). Results are shown as mean \pm SEM. ${ }^{*} \mathrm{P}<0.05 ;{ }^{*} \mathrm{P}<0.01 ;{ }^{*}{ }^{*} \mathrm{P}<0.001$. WT, wild type.

were increased in hTNFtg mice throughout the observation period, beginning from week 4 (figure $3 \mathrm{~B}$ ). These data reveal, that in arthritis prone hTNFtg mice, non-classical monocytes are increased already at the preclinical stage.

Moreover, when we plotted levels of classical or non-classical monocytes in blood against the number of OC found in the hind paws of arthritic mice, we detected a significant correlation between the number of non-classical monocytes in blood and the number of OCs in hind paws $(r=0.64, p=0.02)$. Further, the levels of these cells correlated with the area of inflammatory bone destruction $(r=0.66, p=0.01$; figure $4 A)$ and the area of synovial inflammation $(r=0.65, p=0.02$; figure $4 A)$. In contrast, none of these variables correlated significantly with the number of classical monocytes in peripheral blood (figure 4B).

\section{Non-classical monocytes accumulate at the site of tissue damage}

We next asked, how Ly $6 \mathrm{C}^{+}$cells were distributed in the inflamed synovial membrane and compared this to the general distribution of $\mathrm{CD} 115^{+}$cells. While we did detect $\mathrm{Ly}_{6 \mathrm{C}}^{+}$cells in the arthritic synovial membrane of hTNFtg mice, there were almost no $\mathrm{Ly}_{6 \mathrm{C}}{ }^{+}$cells in the vicinity of erosions (figure 4C). Moreover, OCs stained negative for Ly6C. However, erosions were packed with $\mathrm{CD} 115^{+}$cells, with OCs also expressing CD115. Altogether these data reveal, that OCs in vivo are negative for Ly6C and that also the monocytes/macrophages present in the vicinity of OCs are negative for Ly6C.

To validate the data obtained in hTNFtg animals, we used another arthritis model, namely $\mathrm{K} / \mathrm{BxN}$ serum transfer arthritis. ${ }^{33}$ While we did not detect increased relative numbers of CD11 ${ }^{+}$ cells or $\mathrm{CD}_{115^{+}}$cells in blood or spleens after induction of $\mathrm{K} /$ $\mathrm{BxN}$ serum transfer arthritis (online supplementary figure S2), relative numbers of non-classical monocytes in blood positively correlated with markers of joint destruction (area of erosion and number of OCs) (online supplementary figure S3A). Again, the relative numbers of classical monocytes in blood did not correlate with area of inflammation, area of erosion or number of OC in the hind paw (online supplementary figure S3B). These findings further demonstrate a close correlation of non-classical monocytes with various parameters of bone destruction. We also stained for CD115 and Ly6C in the inflamed hind paws of mice after induction of $\mathrm{K} / \mathrm{BxN}$ serum transfer arthritis. In line with the hTNFtg model, we detected CD $115^{+}$monocytes in the vicinity of bone erosions also in $\mathrm{K} / \mathrm{BxN}$ serum transfer arthritis (online supplementary figure S3C) and OC stained negative for Ly6C.

\section{High osteoclastogenic potential of non-classical monocytes ex vivo}

In order to test the osteoclastogenic potential of the two monocyte subsets, we isolated classical monocytes and non-classical monocytes from blood by FACS and cultured these cells with M-CSF and RANKL. Non-classical monocytes were significantly more potent in differentiating into mature multinucleated OCs than classical monocytes, irrespective of whether the monocytes derived from WT or arthritic hTNFtg mice (figure 5A). In order to investigate potential mechanisms related to the increased osteoclastogenic potential of non-classical monocytes compared with classical monocytes, we tested the global transcriptional response of both monocyte subpopulations to RANKL stimulation. Therefore, we performed RNA sequencing of non-classical monocytes and classical monocytes after 24 hours of RANKL stimulation. Transcriptome analysis revealed a large number of differentially regulated genes (figure $5 \mathrm{~B}, \mathrm{C}$ ). In a gene set enrichment analysis, we detected statistically significant enrichment of all RANKL-induced genes in categories such as metabolic pathways, genes involved in growth, chemotaxis and proliferation as well as OC associated molecular markers in stimulated non-classical monocytes compared with classical monocytes. ${ }^{34}$ 

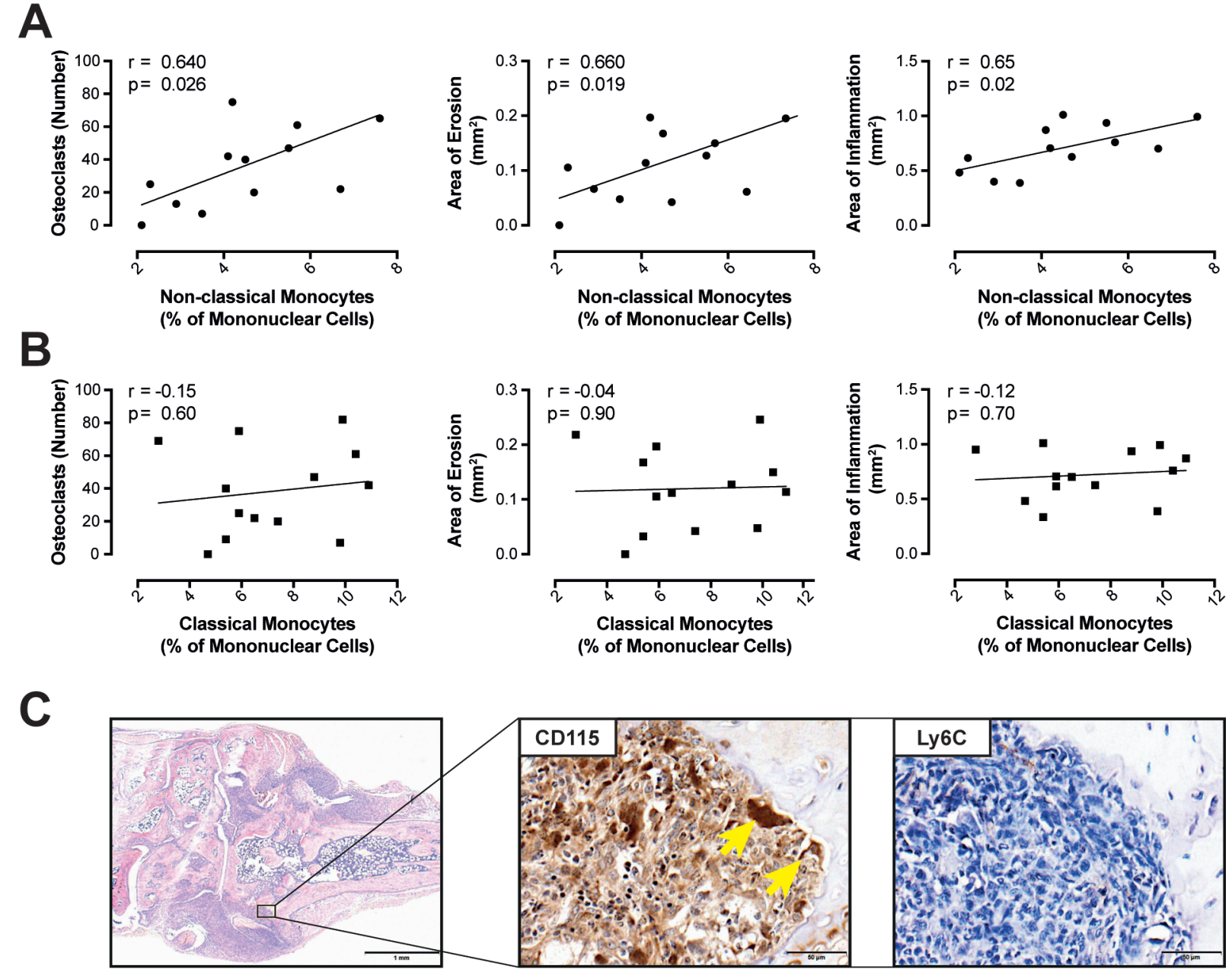

Figure 4 Characterisation of monocytes during hTNF driven arthritis. The number of circulating non-classical monocytes (A) and classical monocytes (B) was correlated with histological markers of joint destruction such as the number of osteoclasts, the area of erosion and inflammation. (C) H\&E staining of a hind paw of a hTNFtg mouse (scale bars $=1 \mathrm{~mm}$ ) and immunohistochemical staining for monocyte markers CD115 and Ly6C in an erosion (scale bars $=50 \mu \mathrm{m}$ ). Arrows indicate CD115 positive osteoclasts.

Vice versa, RANKL-repressed genes were significantly enriched in classical monocytes (online supplementary figure S4).

Gene ontology enrichment analysis showed increased expression of genes associated with the inflammatory response and response to microbial products in classical monocytes compared with non-classical monocytes. In contrast, genes associated with regulation of OC differentiation, iron metabolism and regulation of $\mathrm{pH}$ were enriched in non-classical monocytes (figure 5D).

Of note, we found a significantly increased expression of TRAF6 and Gab2, both proximal adaptors of RANK-mediated signal transduction with well-established roles in osteoclastogenesis, ${ }^{35} 36$ in non-classical monocytes compared with classical monocytes (figure 6A). Increased expression of TRAF6 in non-classical monocytes versus classical monocytes was confirmed by qPCR and at the protein levels by Western blot (figure $6 \mathrm{~B}$ and online supplementary figure S5). We did not detect differences in $\mathrm{c}$-fms or RANK, the respective receptors for M-CSF and RANKL (figure 6C). However, among the differentially expressed genes, we found osteoclast-associated receptor (OSCAR) as well as Osteoclast Stimulatory Transmembrane Protein (OC-Stamp) and dendritic cell-specific transmembrane protein (DC-Stamp), the latter being important molecules regulating the fusion of OCs (figure 6C). ${ }^{37-39}$ We confirmed increased expression of DC-STAMP on non-classical monocytes by Western Blot (figure 6D). We therefore determined the number of nuclei/OC that we found in OCs that had differentiated from non-classical monocytes or classical monocytes. As shown in figure $6 \mathrm{E}$ and $\mathrm{F}$, OC derived from non-classical monocytes exhibited significantly more nuclei than OCs derived from classical monocytes.

\section{DISCUSSION}

Elucidating the mechanisms leading to irreversible joint damage and consequently functional impairment in patients suffering from inflammatory arthritis is of major importance for our understanding of the pathways to severe and disabling disease and for the development of new and even more effective remedies for treating these diseases than available today. In our study, we provide evidence that tissue damage in arthritis is predominantly mediated by non-classical monocytes lacking Ly6C.

The importance of different monocyte subsets in specific diseases, such as autoimmune/autoinflammatory and infectious diseases, has just begun to be appreciated. In many autoimmune models, the role of monocyte subsets in causing disease seems to be quite clear. In colitis, CCR2 ${ }^{+}$monocytes have been established as culprits for tissue damage. ${ }^{1940}$ Similarly, CCR2 ${ }^{+}$ cells are the predominant infiltrating myeloid cells type in experimental autoimmune encephalomyelitis (EAE) and seem 
A

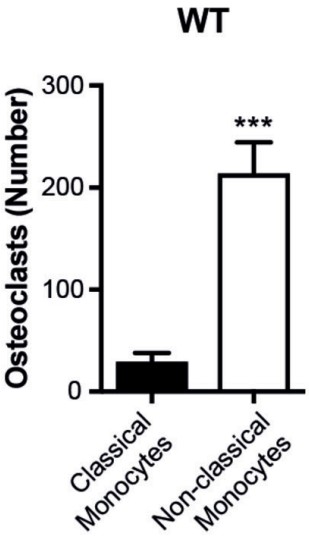

hTNFTg

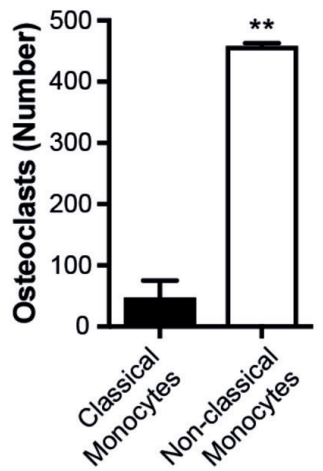

B

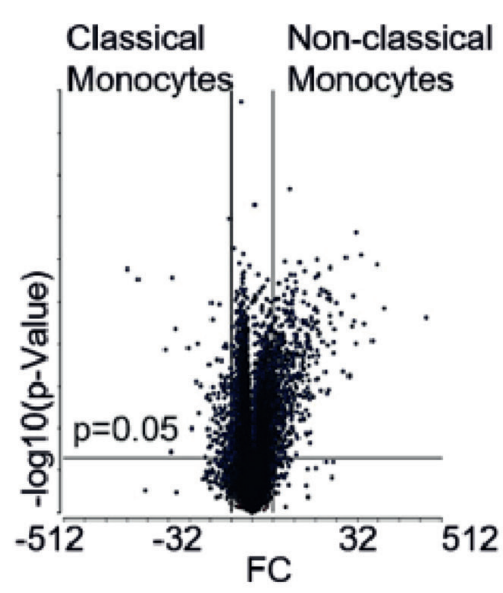

Figure 5 Identification of cell populations with osteoclastogenic potential from peripheral blood cells. (A) In vitro OC assay of sorted Ly6C $\mathrm{C}^{+}$classical and Ly6C $C^{-}$non-classical monocytes of WT and hTNFtg mice stimulated with MCSF (4d) and RANKL (3d). Graph shows the number of TRAP positive multinucleated cells (data shown are mean values of five independent experiments $\pm S E M$ ). (B) Volcano plot representation of differential expression analysis of genes in RNA sequencing of WT Ly6C ${ }^{+}$classical vs Ly6C ${ }^{-}$non-classical monocytes after stimulation with MCSF (4d) and RANKL (1d) ( $n=3$ each). The $x$-axis shows $\log 2 \mathrm{FC}$ in expression, the negative $\log 10$ of the $p$ value is plotted on the $y$-axis. Each gene is represented by one point on the graph. (C) Number of differentially regulated genes ( $F C \geq 2, p \leq 0.05)$ in RNA sequencing in Ly6C $^{+}$classical vs Ly6C $C^{-}$non-classical monocytes. (D) $\mathrm{GO}$ enrichment analysis of the transcriptome of Ly $6 \mathrm{C}^{+}$classical vs Ly6C $\mathrm{C}^{-}$non-classical monocytes: $\mathrm{x}$-axis shows $\mathrm{FC}$ of significantly enriched $\mathrm{GO}$ terms in differentially regulated genes in RNA-sequencing of Ly6C $\mathrm{C}^{+}$classical vs Ly6C $\mathrm{C}^{-}$non-classical monocytes. The number in the columns represents the $-\log 10 \mathrm{p}$ value of the indicated GO term. ${ }^{*} \mathrm{P}<0.01 ;{ }^{* *} \mathrm{P}<0.001$. FC, fold change; GO, Gene Ontology; OC, osteoclasts; TRAP, tartrate-resistant acid phosphatase; WT, wild type.

to be directly responsible for axonal damage, and CCR2-deficient mice are resistant to EAE. ${ }^{18}{ }^{41-43}$ Also in atherosclerosis, CCR2 has been found to be essential in lesion generation. ${ }^{174}$

However, the pathogenesis of inflammatory arthritis seems to be different. It has been already reported that in both CIA as well as arthritis in IL1-RA deficient mice, CCR2 deficiency is associated with an increase in clinical signs and joint damage. ${ }^{25} 26$ In addition, recent evidence also suggests an important role of non-classical Ly6 $\mathrm{C}^{-}$monocytes in the pathogenesis of $\mathrm{K} / \mathrm{BxN}$ serum transfer arthritis, as antibody-mediated depletion of CCR2 ${ }^{+}$cells or in CCR2 deficiency did not alter arthritis development, whereas depletion of monocytes in general or specifically of non-classical monocytes ameliorated disease. ${ }^{21}$ However, there have also been reports suggesting that $\mathrm{Ly} 6 \mathrm{C}^{+}$classical monocytes to mediate tissue destruction in arthritis. ${ }^{22}$ Therefore, the exact role of the two monocyte subsets is still controversial. Here, we have used two common models of inflammatory arthritis. The data obtained show positive correlations of non-classical monocytes with histological parameters of bone destruction in both hTNFtg and $\mathrm{K} / \mathrm{BxN}$ serum transfer arthritis. Of note, we detected only small numbers of $\mathrm{Ly}_{6} \mathrm{C}^{+}$cells in hTNFtg synovitis, which is in agreement with the flow cytometric analyses of Misharin and colleagues in serum transfer arthritis. ${ }^{21}$ Most importantly, 
A

GAB2
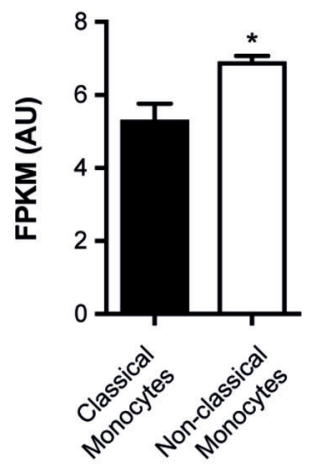

TRAF6

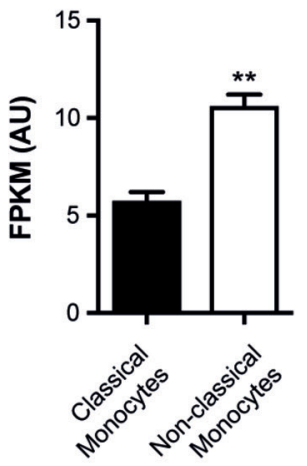

B

$\alpha$-TRAF6

a-Actin

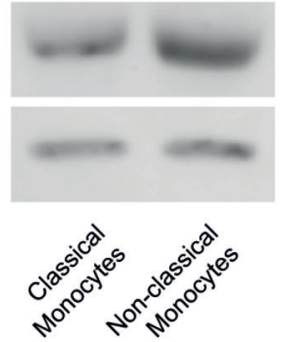

C

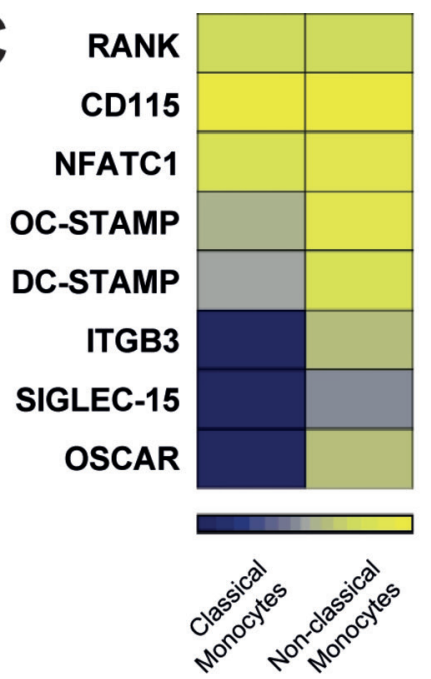

D
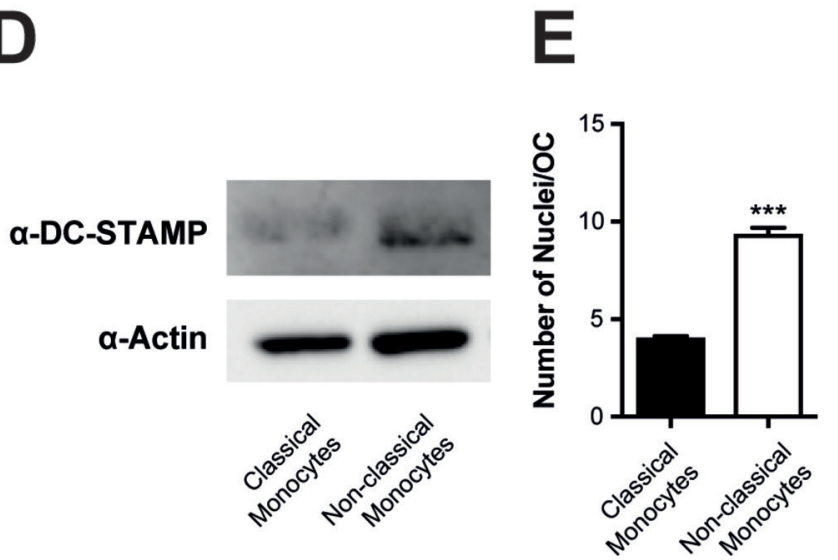

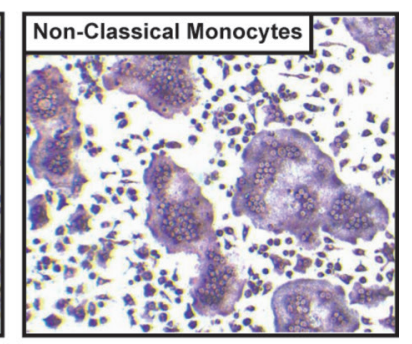

Figure 6 Increased expression of RANK-associated signal transduction molecules in non-classical monocytes. (A) Expression levels (FPKM values) of Gab2 and TRAF6 in RNA sequencing dataset of sorted Ly6C ${ }^{+}$classical and Ly6C ${ }^{-}$non-classical monocytes stimulated with MCSF (4d) and RANKL (1d) ( $n=3$ each). Results are shown as mean \pm SEM (B) Western blot for the presence of TRAF6 in Ly6C ${ }^{+}$classical and Ly6C ${ }^{-}$non-classical monocytes after stimulation with MCSF for 3 days. Actin was used for loading control. Results are representative of three independent experiments. (C) Heat map of osteoclast-related genes of RNA sequencing of classical vs non-classical monocytes stimulated with MCSF (4d) and RANKL (1d) ( $n=3$ each). (D) Western blot for the presence of DC-STAMP in Ly6C ${ }^{+}$classical and Ly6C $\mathrm{C}^{-}$non-classical monocytes after stimulation with MCSF (4d) and RANKL (1d). (E) Quantification of nuclei/OC of classical and non-classical monocytes derived OCs. Results are shown as mean \pm SEM. (F) Representative pictures of TRAP staining to detect $\mathrm{OCs}$ generated from classical and non-classical monocytes. ${ }^{*} \mathrm{P}<0.05$; ${ }^{*} \mathrm{P}<0.01$; ${ }^{* *}{ }^{*} \mathrm{P}<0.001$. 0 Cs, osteoclasts; TRAP, tartrateresistant acid phosphatase.

we demonstrate that non-classical monocytes have a significantly increased potential to differentiate into OC. Analysis of the transcriptional response of these cells to RANKL revealed enrichment of genes involved in iron metabolism in non-classical monocytes. Intriguingly, osteoclastogenesis has been shown to depend on iron, and genes involved in iron metabolism have been shown to be essential in the generation of OC. ${ }^{45}$ In general, RANKL-induced genes were enriched in non-classical monocytes, suggesting an increased responsiveness of non-classical monocytes to RANKL. It will be interesting to bioinformatically compare transcriptional signatures obtained by us with monocytes subpopulations. ${ }^{46}$ In a more detailed analysis, we found components of the RANK-associated signal transduction machinery to be expressed at higher levels in non-classical monocytes versus classical monocytes, most importantly TRAF6 and Gab2. This observation offers a potential molecular explanation for the increased responsiveness to RANKL.

Of note, we also found increased levels of markers regulating fusion of OC, such as DC-STAMP and OC-STAMP. Indeed OCs derived from non-classical monocytes displayed increased numbers of nuclei/OC, suggesting increased potential to form multinucleated cells compared with non-classical monocytes. Interestingly, increased DC-STAMP expression has also been noted in human non-classical $\mathrm{CD} 16^{+}$monocytes, and these cells have been found to be elevated in RA and psoriatic arthritis. $^{47-49}$

Monocytes are of pivotal importance in arthritis. All effective therapies lead primarily to a reduction in synovial monocytes, ${ }^{50}$ and most currently effective targeted therapies interfere with monocyte-derived cytokines, such as TNF and IL-6, their signal transduction or cell-cell interaction. ${ }^{51} 52$ Recognising which subset of monocytes exhibits particularly pathogenic effects is of great importance to develop more specific therapies with potentially less safety issues. Our data identify non-classical monocytes to be both biomarkers of tissue damage as well as direct culprits due to their increased potential to differentiate into OCs. Therefore, these cells might be attractive therapeutic targets.

Acknowledgements We thank Brigitte Meyer for expert technical assistance, Dr George Kollias for providing the hTNFtg mice and the Core Facility Flow Cytometry, Medical University Vienna for their support.

Contributors SB, AP, JSS, MB, TK, MIK, BKP, SH and KR conceived and designed the study. AP, VS, MH, NBB, EG-A, HL, C-WS, BN, JSB, AF and ES performed the 
experiments. YM and JO performed RNA sequencing analysis. SB, AP, SH, BN, MB, KR, MIK, BKP, TK, MC, VS and JM analysed the data. AP, JSB, MH, JSS and SB wrote the final draft. All authors read, revised and approved the final manuscript.

Funding This research has received support from a grant from the Austrian National Bank \#14552 and by the Innovative Medicines Initiative Joint Undertaking under grant agreement $n^{\circ} 115142$ (BTCure) and the Christian Doppler Laboratory for arginine metabolism in rheumatoid arthritis and multiple sclerosis.

Competing interests None declared.

Patient consent Not required.

Provenance and peer review Not commissioned; externally peer reviewed.

Data sharing statement Full RNA-sequencing data are available on request. Open access CCBYNC

(c) Article author(s) (or their employer(s) unless otherwise stated in the text of the article) 2018. All rights reserved. No commercial use is permitted unless otherwise expressly granted.

\section{REFERENCES}

1 Blüml S, Redlich K, Smolen JS. Mechanisms of tissue damage in arthritis. Semin Immunopathol 2014;36:531-40.

2 Scott DL, Pugner K, Kaarela K, et al. The links between joint damage and disability in rheumatoid arthritis. Rheumatology 2000;39:122-32.

3 Komano Y, Nanki T, Hayashida K, et al. Identification of a human peripheral blood monocyte subset that differentiates into osteoclasts. Arthritis Res Ther 2006;8:R152.

4 Kong YY, Feige U, Sarosi I, et al. Activated T cells regulate bone loss and joint destruction in adjuvant arthritis through osteoprotegerin ligand. Nature 1999;402:43-7.

5 Miyamoto T, Ohneda O, Arai F, et al. Bifurcation of osteoclasts and dendritic cells from common progenitors. Blood 2001;98:2544-54.

6 Redlich K, Hayer S, Ricci R, et al. Osteoclasts are essential for TNF-alpha-mediated joint destruction. J Clin Invest 2002:110:1419-27.

7 Teitelbaum SL. Bone resorption by osteoclasts. Science 2000;289:1504-8.

8 Kotani M, Kikuta J, Klauschen F, et al. Systemic circulation and bone recruitment of osteoclast precursors tracked by using fluorescent imaging techniques. J Immunol 2013;190:605-12.

9 Fujikawa Y, Quinn JM, Sabokbar A, et al. The human osteoclast precursor circulates in the monocyte fraction. Endocrinology 1996;137:4058-60.

10 Massey HM, Flanagan AM. Human osteoclasts derive from CD14-positive monocytes. BrJ Haematol 1999;106:167-70.

11 Ritchlin CT, Haas-Smith SA, Li P, et al. Mechanisms of TNF-alpha- and RANKLmediated osteoclastogenesis and bone resorption in psoriatic arthritis. J Clin Invest 2003:111:821-31.

12 Cros J, Cagnard N, Woollard K, et al. Human CD14dim monocytes patrol and sense nucleic acids and viruses via TLR7 and TLR8 receptors. Immunity 2010:33:375-86.

13 Ziegler-Heitbrock L. Monocyte subsets in man and other species. Cell Immunol 2014:289:135-9.

14 Mitchell AJ, Roediger B, Weninger W. Monocyte homeostasis and the plasticity of inflammatory monocytes. Cell Immunol 2014;291:22-31.

15 Serbina NV, Pamer EG. Monocyte emigration from bone marrow during bacteria infection requires signals mediated by chemokine receptor CCR2. Nat Immunol 2006;7:311-7.

16 Tsou CL, Peters W, Si Y, et al. Critical roles for CCR2 and MCP-3 in monocyte mobilization from bone marrow and recruitment to inflammatory sites. J Clin Invest 2007;117:902-9.

17 Boring L, Gosling J, Cleary M, et al. Decreased lesion formation in CCR2-/mice reveals a role for chemokines in the initiation of atherosclerosis. Nature 1998;394:894-7.

18 Izikson L, Klein RS, Charo IF, et al. Resistance to experimental autoimmune encephalomyelitis in mice lacking the CC chemokine receptor (CCR)2. J Exp Med 2000:192:1075-80.

19 Zigmond E, Varol C, Farache J, et al. Ly6C hi monocytes in the inflamed colon give rise to proinflammatory effector cells and migratory antigen-presenting cells. Immunity 2012:37:1076-90

20 Blüml S, Binder NB, Niederreiter B, et al. Antiinflammatory effects of tumor necrosis factor on hematopoietic cells in a murine model of erosive arthritis. Arthritis Rheum 2010;62:1608-19.

21 Misharin AV, Cuda CM, Saber R, et al. Nonclassical Ly6C(-) monocytes drive the development of inflammatory arthritis in mice. Cell Rep 2014;9:591-604.

22 Seeling M, Hillenhoff U, David JP, et al. Inflammatory monocytes and Fcy receptor IV on osteoclasts are critical for bone destruction during inflammatory arthritis in mice. Proc Natl Acad Sci U S A 2013:110:10729-34.
23 Binder NB, Niederreiter B, Hoffmann O, et al. Estrogen-dependent and C-C chemokine receptor-2-dependent pathways determine osteoclast behavior in osteoporosis. Nat Med 2009;15:417-24.

24 Yao Z, Li P, Zhang Q, et al. Tumor necrosis factor-alpha increases circulating osteoclast precursor numbers by promoting their proliferation and differentiation in the bone marrow through up-regulation of c-Fms expression. J Biol Chem 2006;281:11846-55.

25 Fujii H, Baba T, Ishida Y, et al. Ablation of the Ccr2 gene exacerbates polyarthritis in interleukin-1 receptor antagonist-deficient mice. Arthritis Rheum 2011;63:96-106.

26 Quinones MP, Ahuja SK, Jimenez F, et al. Experimental arthritis in CC chemokine receptor 2-null mice closely mimics severe human rheumatoid arthritis. J Clin Invest 2004;113:856-66

27 Keffer J, Probert L, Cazlaris H, et al. Transgenic mice expressing human tumour necrosis factor: a predictive genetic model of arthritis. Embo J 1991;10:4025-31.

28 Blüml S, Bonelli M, Niederreiter B, et al. Essential role of microRNA-155 in the pathogenesis of autoimmune arthritis in mice. Arthritis Rheum 2011;63:1281-8.

29 Blüml S, Friedrich M, Lohmeyer T, et al. Loss of phosphatase and tensin homolog (PTEN) in myeloid cells controls inflammatory bone destruction by regulating the osteoclastogenic potential of myeloid cells. Ann Rheum Dis 2015:74:227-33.

30 Ashburner M, Ball CA, Blake JA, et al. Gene ontology: tool for the unification of biology. The Gene Ontology Consortium. Nat Genet 2000;25:25-9.

31 The Gene Ontology Consortium. Expansion of the Gene Ontology knowledgebase and resources. Nucleic Acids Res 2017;45:D331-D8.

32 Yates B, Braschi B, Gray KA, et al. Genenames.org: the HGNC and VGNC resources in 2017. Nucleic Acids Res 2017:45:D619-D625.

33 Korganow AS, Ji H, Mangialaio S, et al. From systemic T cell self-reactivity to organspecific autoimmune disease via immunoglobulins. Immunity 1999;10:451-61.

34 Yang G, Zaidi M, Zhang W, et al. Functional grouping of osteoclast genes revealed through microarray analysis. Biochem Biophys Res Commun 2008;366:352-9.

35 Wada T, Nakashima T, Oliveira-dos-Santos AJ, et al. The molecular scaffold Gab2 is a crucial component of RANK signaling and osteoclastogenesis. Nat Med 2005;11:394-9.

36 Lomaga MA, Yeh WC, Sarosi I, et al. TRAF6 deficiency results in osteopetrosis and defective interleukin-1, CD40, and LPS signaling. Genes Dev 1999:13:1015-24.

37 Kukita T, Wada N, Kukita A, et al. RANKL-induced DC-STAMP is essential for osteoclastogenesis. J Exp Med 2004:200:941-6.

38 Yagi M, Miyamoto T, Sawatani Y, et al. DC-STAMP is essential for cell-cell fusion in osteoclasts and foreign body giant cells. J Exp Med 2005;202:345-51.

39 Yang M, Birnbaum MJ, MacKay CA, et al. Osteoclast stimulatory transmembrane protein (OC-STAMP), a novel protein induced by RANKL that promotes osteoclast differentiation. J Cell Physiol 2008:215:497-505.

40 Platt AM, Bain CC, Bordon Y, et al. An independent subset of TLR expressing CCR2-dependent macrophages promotes colonic inflammation. J Immunol 2010;184:6843-54.

41 Fife BT, Huffnagle GB, Kuziel WA, et al. CC chemokine receptor 2 is critical for induction of experimental autoimmune encephalomyelitis. J Exp Med 2000;192:899-906.

42 Saederup N, Cardona AE, Croft K, et al. Selective chemokine receptor usage by central nervous system myeloid cells in CCR2-red fluorescent protein knock-in mice. PLoS One 2010;5:e13693.

43 Yamasaki R, Lu H, Butovsky O, et al. Differential roles of microglia and monocytes in the inflamed central nervous system. J Exp Med 2014;211:1533-49.

44 Barlic J, Murphy PM. Chemokine regulation of atherosclerosis. J Leukoc Biol 2007;82:226-36

45 Ishii KA, Fumoto T, Iwai K, et al. Coordination of PGC-1 beta and iron uptake in mitochondrial biogenesis and osteoclast activation. Nat Med 2009;15:259-66.

46 Mildner A, Schönheit J, Giladi A, et al. Genomic Characterization of Murine Monocytes Reveals C/EBP $\beta$ Transcription Factor Dependence of Ly6C Cells. Immunity 2017;46:849-62.

47 Chiu YH, Mensah KA, Schwarz EM, et al. Regulation of human osteoclast development by dendritic cell-specific transmembrane protein (DC-STAMP). J Bone Miner Res 2012:27:79-92.

48 Kawanaka N, Yamamura M, Aita T, et al. CD14+,CD16+ blood monocytes and joint inflammation in rheumatoid arthritis. Arthritis Rheum 2002:46:2578-86.

49 Chiu YG, Shao T, Feng C, et al. CD16 (FcRgammalll) as a potential marker of osteoclast precursors in psoriatic arthritis. Arthritis Res Ther 2010;12:R14.

50 Tak PP. Analyzing synovial tissue samples. What can we learn about early rheumatoid arthritis, the heterogeneity of the disease, and the effects of treatment? I Rheumatol Supp/ 2005;72:25-6.

51 Redlich K, Smolen JS. Inflammatory bone loss: pathogenesis and therapeutic intervention. Nat Rev Drug Discov 2012:11:234-50.

52 Meier FM, Frerix M, Hermann W, et al. Current immunotherapy in rheumatoid arthritis. Immunotherapy 2013:5:955-74. 